\title{
Músicos, acción y contexto: reconstruyendo la escena musical porteña desde la trayectoria biográfica del empresario Pablo Rosquellas
}

Guillermina Guillamon

Instituto de Estudios Históricos, Universidad Nacional de Tres de Febrero; Consejo de Investigaciones Científicas y Técnicas, Argentina guillermina.guillamon@gmail.com

Artículo recibido: 19 de septiembre de 2018. Aprobación final: 11 de febrero de 2019.

\section{Resumen}

El presente artículo parte de la reconstrucción de la trayectoria de Pablo Rosquellas, músico y empresario teatral español que vivió en Buenos Aires entre 1823 y 1831. Este punto de partida nos conduce al objetivo del trabajo: mostrar cómo el análisis de las acciones que desplegaron músicos y empresarios permite complejizar -al tiempo que discutir- una visión que establece a las prácticas culturales de la élite porteña como la consecuencia del accionar modernizador y reformista del grupo rivadaviano.

En este sentido, la trayectoria biográfica de Rosquellas nos posibilita desplazar el foco de análisis de la política rivadaviana y situarlo en la dinámica de la cultura musical porteña, particularmente en la consolidación de la ópera buffa. Así, es posible advertir que la conformación de una escena musical moderna -que trascendió las fronteras de la provincia y se insertó en una cultura artística global vinculada a la ópera-, antes que la consecuencia de un programa cultural preestablecido por el poder político rivadaviano, fue el resultado de un entramado de acciones situadas y con grados de especificidad de diversos actores musicales.

Palabras clave: músicos; trayectoria; acción; cultura musical.

Musicians, Action and Context: Reconstructing the Musical Scene of Buenos Aires from the Biographical Trajectory of the Entrepreneur Pablo Rosquellas 


\section{Abstract}

This article is based on the reconstruction of the career of Pablo Rosquellas, a Spanish theater musician and businessman who lived in Buenos Aires between 1823 and 1831. This leads us to the objective of this work: to show how the analysis of the actions deployed by musicians and businessmen allows us to discuss a perspective that establishes the cultural practices of the Buenos Aires elite as the consequence of the modernizing and reformist actions of the Rivadavian group.

In this sense, the biographical trajectory of Rosquellas allows us to displace the focus of analysis of the political program and to situate it in the dynamics of the Buenos Aires musical culture, particularly in the consolidation of opera buffa. Thus, we stress that the conformation of a modern musical scene during the period under analysis was more the result of a network of actions managed by diverse musical actors, rather than the consequence of a cultural program preestablished by the Rivadavian political power.

Keywords: musicians; action; trajectory; musical culture.

\section{Introducción}

El 27 de septiembre de 1825 se representó en el teatro Coliseo Provisional de Buenos Aires la primera ópera completa: El Barbero de Sevilla, de Gioachino Rossini. Su estreno evidenció la configuración de un nuevo gusto musical, ahora ligado a la lírica italiana en detrimento de los géneros españoles, tales como la tonadilla y el sainete. ${ }^{1}$ Sin embargo, ¿Cuáles fueron los actores implicados en el impulso y promoción de lo musical como una práctica constitutiva de las -ahora- sociedades modernas? ¿Qué estrategias y cursos de acción desarrollaron empresarios, instrumentistas y cantantes de la escena musical para consolidar su práctica al tiempo que transformar el gusto musical? Responder a estos interrogantes nos obliga a reconstruir la escena musical porteña y, más específicamente, a restituir a los actores involucrados en ella.

El presente artículo parte de la reconstrucción de la trayectoria de Pablo Rosquellas, músico y empresario teatral español que vivió en Buenos Aires entre 1823 y 1831. Este punto de partida nos conduce a uno de los objetivos de este trabajo: mostrar cómo el análisis de las acciones que desplegaron músicos y empresarios nos aleja de un contexto homogéneo, unificado, el cual condicionaría a los sujetos. Atender a los cursos de acción que llevaron a cabo los actores de la escena musical nos permite, en suma, dar cuenta de momentos y trayectorias mucho más complejas y diversas, que exceden a los modelos y categorías universalizadoras y estáticas.

1 Más allá del reto que exige montar una ópera completa, la pertinencia de preguntarse sobre su consolidación como género reside en que, de forma comparativa, es llamativa la precocidad del proceso. Tanto en Chile como en Uruguay, la primera ópera representada de forma completa fue El engaño feliz en 1830, cuatro años después de su estreno en Buenos Aires. Sin embargo, la ópera no se consolidó hasta la creación del Teatro Municipal (1857) en Chile y del teatro Solís (1856) en Uruguay. Otro ejemplo paradójico fue el caso mexicano: El Barbero de Sevilla fue representada en México en 1827. Cfr. Carredaño (2010: 153- 219). 
Este recorrido pretende complejizar una visión que sitúa a las prácticas culturales como la consecuencia de la implementación de programas políticos modernos, más específicamente como el resultado directo de una agenda de reformas modernizadoras en Buenos Aires durante la década de 1820. Situados en este punto, es posible advertir que para abordar la conformación de la escena musical porteña, caracterizada a su vez por la afición a la ópera buffa, es necesario analizar un entramado de acciones situadas y específicas de diversos actores musicales. En este mismo sentido, es necesario resaltar que músicos, empresarios y cantantes desarrollaron diversos cursos de acción en distintas dimensiones de lo social que, muchas veces, excedieron lo musical y se vincularon con instituciones políticas.

Por ello, se busca reconstruir la trayectoria de uno de los principales actores de la escena musical porteña, atendiendo no sólo a las posiciones objetivas transitadas y ocupadas, a la conformación e incorporación de habitus y a la posesión de los bienes simbólicos en lo que -debe señalarse- aún no conformaba un campo. ${ }^{2}$ Para complejizar esta visión, se retoma el supuesto de que las trayectorias -caracterizadas por la interdependencia- sólo se pueden comprender si se reconstruye el tejido de lazos sociales -las configuraciones- que vinculan a los individuos entre sí (Elias, 1991). Por otro lado, este recorrido nos permite reponer un debate teórico que prioriza la propia acción - plural y diversa- de los individuos en la reconstrucción de las trayectorias y los contextos sociales. Indagar en torno a qué hacían los actores musicales nos conduce a la descripción del mundo que habitaron y en donde dichas acciones cobran sentido.

A modo de problematizar lo expuesto, el trabajo se divide en cuatro partes. En un primer momento se reconstruye la trayectoria de Pablo Rosquellas, tomando para ello un relato biográfico. Asimismo, en dicho apartado se introducirán las principales herramientas teóricas y metodológicas que nos permiten complejizar dicha construcción/narración biográfica. A partir de ello, se busca analizar dos dimensiones de la trayectoria del músico. En un segundo apartado, se reconstruyen los lazos y vinculaciones que estableció hacia el interior del Teatro Coliseo Provisional, la gestión del espacio teatral, la compañía lírica y la programación musical. En el tercer apartado, se problematiza la agencia del músico respecto de los derechos laborales, específicamente las disputas que entabló con el gobierno y la policía en torno a reglamentos y contratos a fin de convertirse en asentista. El último apartado intenta sistematizar el recorrido, a fin de dar cuenta cómo el estudio de caso, guiado a su vez bajo un enfoque que prioriza la agencia de los individuos, permite restituir las múltiples experiencias de los actores. De forma complementaria, ofrece la posibilidad de reconstruir un mundo cultural -en tanto prácticas, representaciones y saberes- que no necesariamente se relacionan unidireccionalmente con las voluntades y lineamientos políticos.

2 Es menester destacar que si bien partimos de los trabajos que señalan las limitaciones del enfoque biográfico, no por ello se pretende aquí retomar la totalidad de sus supuestos teóricos. Respecto de las principales críticas al enfoque véase: Passeron (1989), Bourdieu (1989), Dosse (2007). 


\section{La (de)construcción de una ilusio biográfica y consideraciones teóricas para complejizar las trayectorias}

Mariano Pablo Rosquellas nació en Madrid en 1790 y se formó en violín y canto en Italia. Trabajó como músico en la Capilla Real de Madrid hasta 1817, momento en el cual conoció a la que sería su segunda esposa, Leticia de Lacy (había enviudado de Polonia Muñoz, con quien había tenido dos hijos). ${ }^{3}$ Producto del enfrentamiento entre un tío de su pretendida contra el absolutismo monárquico -hecho que le valió el fusilamiento-, ambos debieron abandonar España por ser considerados liberales y partieron hacia Londres, ciudad donde Rosquellas trabajaría por pocos meses. En 1818 se casó con Leticia de Lacy en Irlanda, y juntos se embarcaron hacia el Brasil portugués para trabajar en Río de Janeiro, ciudad que crecía artísticamente al calor del impulso de los reyes y la corte portuguesa. Allí establecieron un fuerte vínculo con Pedro I, dado que éste tenía conocimiento de que Leticia era familiar de un diplomático que se encontraba realizando tareas en dicha ciudad. Desde 1819, Rosquellas trabajó en el flamante Real Teatro de São João junto a otros cantantes de origen italiano. A partir de 1820, la Compañía lírica comenzó a representar con sistematización óperas buffas, obras que serían montadas en Buenos Aires pocos años después. Lejos de perdurar, la experiencia lírica en Río de Janeiro finalizó con el incendio del Teatro local, en 1824.

Meses previos al incendio, Pablo Rosquellas había viajado a la ciudad de Buenos Aires. En su visita, en 1823, se presentó en el Coliseo Provisional, hecho que suscitó enorme repercusión en la prensa porteña. Posteriormente a dicho episodio, Rosquellas dejó Río de Janeiro y se radicó junto a familia en Buenos Aires, pero también con algunos de los cantantes italianos que habían trabajado en Brasil. El escenario porteño no sólo se presentaba fértil en el ámbito musical desde 1817 -momento en el que se había formado la Sociedad del Buen Gusto por el Teatro-, sino también alentador en la dimensión política. Una elite ilustrada, con el proyecto de consolidar un régimen político moderno, veía en la ópera un soporte capaz de civilizar las costumbres y el gusto e instituir nuevos vínculos de sociabilidad entre los ahora ciudadanos. A su vez, ello permitiría a Buenos Aires asemejarse a las ciudades ilustradas europeas: al tiempo que le mostraba a las provincias que el progreso era posible, Buenos Aires se erigía a sí misma como la encargada de ser la ciudad ejemplar ante el interior atrasado y atravesado por los enfrentamientos facciosos.

En 1824 Pablo Rosquellas formó una compañía lírica y comenzó a intervenir en el Teatro Coliseo Provisional hasta convertirse en su asentista, juicio civil mediante con el antiguo empresario teatral. Un año después, Rosquellas comenzó a desarrollar una programación musical que tuvo como eje fundamental a las

3 La presente biografía fue reconstruida teniendo en consideración una serie investigaciones editas, como así también diversas fuentes que conforman el corpus documental del presente artículo. Respecto de la consulta bibliográfica: Bosch (1905), Gesualdo (1961); Plesch-Huseby (1999), Carredaño-Eli (2010: 153-219). Cabe resaltar la ausencia de trabajos posteriores sobre las prácticas musicales en general, y sobre los actores de la escena en particular. En relación a esta carencia, debemos advertir que no obstante las falencias de un relato cuyo interés principal era demostrar la evolución de la música hacia los parámetros de cánones y gusto europeos, los trabajos de Vicente Gesualdo fueron erigidos -hasta hace poco tiempo-como fundacionales en los estudios de la historia de la música. 
óperas buffas de Gioacchino Rossini, y como protagonista a su Compañía Lírica. La prensa porteña promocionó y reseñó sistemáticamente las funciones, al tiempo que erigió a Rosquellas como "el padre de la ópera en Buenos Aires". Los años de esplendor de la lírica italiana en el Teatro encontraron un correlato en la afición del público por la ópera buffa, haciendo que las representaciones se realizaran, casi en su totalidad, a sala llena.

Sin embargo, a comienzos de 1830, la coyuntura económica, la inestabilidad política y la falta de regulación e impulso al Teatro, impactaron en el desarrollo de las funciones líricas. Los principales cantantes dejaron la Compañía y probaron suerte en Montevideo, Valparaíso, Santiago de Chile, e incluso nuevamente en Río de Janeiro. Lo mismo sucedió con Rosquellas, a pesar de que volvería a Buenos Aires para cantar arias de óperas en el Coliseo y componer canciones, soporte de moda por aquel entonces. Pero otros músicos e intelectuales, vinculados a la denominada "joven generación romántica", serían los nuevos referentes en la escena. En 1833, y en una completa bancarrota derivada de sus inversiones teatrales, Rosquellas se fue a Sucre, donde viviría hasta su muerte.

Hasta aquí un relato biográfico, una narración consecuente de hechos -con una linealidad subyacente- que nos posibilita comenzar a problematizar la trayectoria del músico. Sin embargo, ¿Cómo reponer las posiciones que asumió en las diversas dimensiones de su labor artística, pero también empresarial? ¿Con qué herramientas analizar las experiencias que desarrolló en Buenos Aires y su vinculación con la configuración de un stock de esquemas de acción? ¿Cómo reconstruir el contexto priorizando un análisis del sentido que los actores le otorgan a sus acciones? Partiendo de estas preguntas de corte teórico-metodológicas, a continuación realizaremos una serie de consideraciones que nos permiten reflexionar sobre el potencial que tienen los estudios de casos en el campo de las ciencias sociales y, particularmente, de cómo este tipo de enfoques ponen en un primer plano las dimensiones que nos posibilitan ver a los sujetos en acción. ${ }^{4}$

Tal como ha mostrado la microhistoria, el estudio de determinadas trayectorias permite invertir la escala de análisis y reconstruir contextos y procesos de más largo alcance, anulando la diferencia entre micro y macro. ${ }^{5}$ Pero, por sobre ello, este tipo de análisis posibilita reconstruir aquello que la microhistoria denominó sistema de contexto: las incertidumbres de las elecciones, que descomponen las realidades articuladas en un solo tiempo, restituyen las múltiples situaciones en

4 Sobre una reflexión desde la historiografía acerca del (re)surgimiento de la biografía, de la influencia de la "sociología de la acción" y del giro teórico y metodológico que ello conlleva, véase Morales Moya (2008: 91-100)

5 Asimismo, la microhistoria ha reflexionado en torno a las limitaciones de las fuentes, específicamente sobre la mediación que supone la intervención de sujetos de la cultura dominante y que convierte a la fuente es un documento opaco, deformado. Pero aún en esta complejidad hay una certeza: de la cultura y de su condición social no escapa nadie. Derivado de este supuesto, se entiende que las fuentes ofrecen huellas, indicios que pueden constituir un hilo a través del cual reconstruir las experiencias y representaciones propias de las culturas populares. En este sentido, la propuesta del paradigma indiciario es expuesta en Guinzburg (2014). Específicamente véase la Introducción (pp. 9-18) y el capítulo "El inquisidor como antropólogo" (pp. 395-412). 
las cuales el sujeto pudo reorganizar su experiencia y configurar su estrategia pese a la rigidez de las estructuras políticas o ideológicas (Bensa, 2015: 60).

No obstante los aportes de dicha perspectiva historiográfica, nos interesa aquí poner el énfasis en las acciones desplegadas por los sujetos, en tanto que al tiempo que nos posibilita analizar los entramados, las redes, las vinculaciones en contexto (Latour, 2008), permite a la vez reconstruir cómo determinadas formas de sentir, pensar y actuar se estabilizan hasta convertirse en disposiciones individuales. Sin embargo, no queremos limitar este último aspecto al concepto de habitus bourdeano, ya que creemos que ello nos conduciría a pensar que hay una correlación necesaria entre las estructuras objetivas, las posiciones que ocupa el sujeto en los campos y las disposiciones mismas (Bourdieu, 1991: 92). ${ }^{6}$ Asimismo, el concepto de campo presenta sus limitaciones para pensar la sociedad rioplatense de principios de siglo XIX. Específicamente, refiriéndonos al campo artístico, y en particular al musical, no nos es posible establecer límites claros y autónomos, saberes propios, ni instituciones de enseñanza y titulación netamente estatales, entre otros. Por lo demás, ello se vincula con la dificultad para establecer una división clara entre el ámbito de lo público y de lo privado, aún en constante solapamiento y redefinición durante el recorte temporal propuesto (Myers, 1999; Molina, 2006).

Para sortear el condicionante propio del habitus y las limitaciones del concepto de campo, proponemos aquí retomar los aportes de Bernard Lahire, quien propone pensar que el actor social incorpora una multiplicidad de esquemas de acción que se organizan y se utilizan en el contexto que él mismo considere pertinente. En consecuencia, todo actor incorpora un abanico de hábitos modelados en una diversidad de experiencias socializadoras que no se corresponden unidireccionalmente con campos sociales estables y diferenciados. Es, en suma: “(...) un actor con un stock de esquemas de acción o de hábitos no homogéneos, no unificados, y, en consecuencia, con prácticas heterogéneas (e incluso contradictorias) que varían según el contexto social en que se vea obligado a evolucionar" (Lahire, 2004:46-47).

En este sentido, creemos que uno de los trabajos que superó la dicotomía establecida entre actor y sociedad, individuo y grupo para, en su lugar, analizar la relación entre las experiencias individuales y los procesos sociales de larga duración es Mozart. Sociología de un genio, de Norbert Elias (1991). El estudio sobre Mozart, más que realizar una reconstrucción biográfica, pretende mostrar que la trayectoria -la interdependencia- del músico vienés sólo se puede comprender si se reconstruye el tejido de lazos sociales -las figuraciones- en las que éste se insertó. De aquí su premisa socio-histórica más amplia: los sujetos, lejos de ser autónomos, son interdependientes y esas dependencias recíprocas que los ligan dan lugar a configuraciones (Corcuff, 2015: 35-40).

6 Por otra parte, la propuesta bourdeana de habitus impone limitaciones para concebir a lo individual como una categoría de análisis, en tanto esta dimensión, de acuerdo a su perspectiva, sólo puede ser concebida como una individuación de esquemas colectivos (Corcuff, 2005: 128). En consecuencia, y tal como han advertido diversos autores, si bien Bourdieu puede explicar la presencia de lo colectivo en lo individual, no logra dar cuenta de los cambios en el sujeto a través del tiempo ni de las desviaciones respecto de un grupo (Benzecry, 2017: 15). 
En suma, la reconstrucción de la trayectoria de Pablo Rosquellas que se presenta a continuación sitúa la atención en el curso de la acción para, a partir de ella, reconstruir la realidad social y sus múltiples dimensiones De este modo, indagar en torno a qué hicieron los actores de la escena musical nos conduce a la descripción del mundo que habitaron: es en la propia acción en donde se construye el contexto en el que dichas acciones cobran sentido (Garzón Rogé, 2017: 17-20).

\section{Vinculaciones, decisiones y recursos: Pablo Rosquellas y el desarrollo de una cultura musical porteña durante 1820}

Hacia inicios de la década de 1820, comenzaba a desarrollarse en Buenos Aires un gobierno provincial que al tiempo que buscaba consolidar un nuevo orden político-institucional -ahora autónomo de las provincias- tenía como horizonte de acción la concreción de una transformación modernizadora de la sociedad. En consecuencia, la "feliz experiencia" se caracterizó por la implementación de una amplia agenda de reformas tendientes a erigir un régimen político que fuese estable, legítimo y moderno. En este marco, el principal objetivo que postuló el programa rivadaviano fue el de dominar las pasiones bárbaras de una mayoría incivilizada, a fin de instaurar un gobierno que permitiese a Buenos Aires erigirse como el portador de la civilidad y, consecuentemente, como un modelo a ser imitado por las provincias (Gallo y Batticuore, 2013). Pero fue particularmente en el ámbito de las medidas culturales adoptadas e implementadas donde el naciente estado provincial se instituyó como el encargado de modificar las conductas de los que, consideraban, eran ahora ciudadanos.

Con este fin -y en concordancia con el ideario ilustrado-, el gobierno de Buenos Aires impulsó instancias asociativas y espacios públicos en los cuales concretar y hacer extensivas sus reformas, al tiempo que limitar las reuniones el ámbito de lo privado (Aliata, 2006). Asimismo, la ambición política de reformar costumbres y hábitos sociales no sólo supuso la consolidación de nuevos espacios y prácticas sino que, de forma complementaria, conllevó la configuración discursiva de un estándar normativo de "buen gusto". La convicción política de reformar las conductas de los ciudadanos para elevar a la ciudad de Buenos Aires hasta convertirla en un caso "ejemplificador", coincidió con la idea de que el buen gusto en las artes contribuiría al progreso de la moral y del bienestar del individuo. Pero, por sobre todo, se esperó que el buen gusto estético contribuyera al progreso colectivo de la sociedad: al tiempo que habilitó atributos y capacidades derivadas del pleno ejercicio de la razón, canceló aquellas que, según consideró la crítica, obstaculizaban el camino hacia un nuevo orden político-institucional (Guillamon, 2016).

Cabe señalar que el Teatro Coliseo Provisional fue promocionado en la prensa porteña en base a dos dimensiones fundamentales: por un lado, se hizo hincapié en la precariedad edilicia, dada la contradicción que suponía realizar allí prácticas artísticas civilizadas como la música; y, por otro, en los avances logrados en torno a la programación musical y teatral que permitían dejar atrás el gusto por obras 
españolas. Así, si constituía un espacio mediante el cual "pulir las costumbres" y difundir ideas y un gusto ilustrado, el alegato frecuentemente esgrimido en la prensa fue la necesidad de ostentar un teatro que fuese capaz de demostrar la condición civilizada de la que sería poseedora Buenos Aires. En este sentido, es posible indicar un creciente interés por su reforma material a partir de 1816 -momento en el cual Juan Martín de Pueyrredon, por entonces Director Supremo de las Provincias Unidas del Río de la Plata, conformó la Sociedad del Buen Gusto por el Teatro $-^{7}$; de hecho, su precariedad edilicia constituyó un problema que tuvo continuidad a lo largo de las décadas de 1820 y 1830.

En relación a las prolongadas quejas en torno a la precariedad del espacio teatral, el diario El Argentino afirmó que la intervención tanto de empresario particulares como del mismo Estado era de suma urgencia dado que el teatro permitía “(...) inflamar el patriotismo, como para mejorar las costumbres de un pueblo civilizado (...). Esto hace más necesario el estado en el que se halla: necesita mejoras, que los escritores públicos se fijen en el, lo observen y noten lo bueno para estimularlo". Por su parte, el diario El Teatro de la Opinión también intervino en el reclamo. En una nota escrita por quienes se autodenominaron como "los amantes del teatro", se publicó una extensa crítica al manejo del asentista del Teatro -por ese entonces, Antonio Pereyra- y a la falta de interés del gobierno por mejorar un espacio que “(...) en todos los pueblos civilizados es el barómetro de su cultura, su delicadeza y su moral (...)”. Por último, nos interesa señalar el paradójico posicionamiento de El Argos de Buenos Aires, diario que se caracterizó por publicar extensas reseñas sobre las actividades desarrolladas en el Coliseo Provisional. Si bien afirmó que “(...) la reforma y mejora de nuestro teatro no andan a la par con las demás instituciones del país (...)”, en sus números están ausentes las críticas al accionar de los asentistas y al estado material del Coliseo Provisional. ${ }^{10}$

Refiriéndose al cambio en la programación, particularmente a la sustitución de obras barrocas por arias italianas, El Abogado Nacional señaló que "no puede presentarse un mejor convencimiento del grado de refinamiento que ha adquirido en esta Ciudad el gusto público, y de los grandes adelantamientos de la ilustración, que el estado actual de sus teatro". ${ }^{11}$ En este mismo plano, fue frecuente la comparación del Coliseo -particularmente por la representación de óperas buffas completas- con los teatros europeos: "Es verdad que ha sido necesario luchar con mil obstáculos, que era preciso vencer, pero ellos han sido vencidos apareciendo en nuestro proscenio una de las composiciones mas [sic] difíciles de ejecutarse, aun en los grandes teatros de Europa". ${ }^{12}$

7 Sobre un análisis de la conformación y devenir de dicha Sociedad, como así también la intervención de literatos y políticos en dicho espacios, véase: Guillamon (2015a).

8 (13 de Agosto de 1825). El Argentino, Buenos Aires, núm. 27.

9 (6 de agosto de 1824). El Teatro de la Opinión, Buenos Aires, núm. 8. Este aspecto ha sido analizado en: Guillamon (2017: 38-39).

10 La crítica al estado material del Teatro Coliseo Provisional fue abordada en Guillamon (2015a)

11 (10 de mayo de 1819). El Abogado Nacional, Buenos Aires, núm. 10.

12 (24 de abril de 1827). El Constitucional, Buenos Aires, núm. 4. 
En este contexto socio-político, comenzó a desarrollarse un proceso de características inusitadas en Buenos Aires: la progresiva y sistemática introducción de obras instrumentales y cantadas en la programación del Coliseo Provisional -nunca antes ejecutadas en la ciudad- que derivaría, luego de varios años, en la consolidación de la ópera buffa rossiniana. Aunque este desarrollo musical concordaba con los objetivos modernizadores del gobierno, el responsable de dinamizar el Teatro Coliseo Provisional fue un músico español que, siendo ajeno al poder político, lograría establecerse como uno de los agentes culturales de mayor importancia en la escena musical porteña: Mariano Pablo Rosquellas.

La primera mención a este músico se realizó hacia fines de febrero 1823 en el diario El Centinela, con un anuncio que promocionaba su concierto de presentación. Si bien no hay referencias en la prensa que den cuenta del momento en que Rosquellas regresó a Río de Janeiro con motivo de contratar a cantantes e instrumentistas, Goyena (2003) ha estimado que dicho viaje se habría realizado en 1822, y que habría regresado hacia mediados de 1823. Respecto de esta datación, se puede agregar que luego de la mención a Rosquellas en El Centinela, el mismo diario, con fecha de marzo, explicitó que la intención política del gobierno de promover el ámbito de las artes y dinamizar el mundo teatral, permitió que estas confluyeran en un nuevo impulso a la cultura musical:

En la época precisa en que el Gobierno ha dejado traslucir su deseo de establecer y fomentar un teatro nacional nos ha venido una sucesión de artistas (...) cantores, músicos y danzantes. Las habilidades de algunos de estos nos hacen olvidar por momentos de nuestra posición geográfica, y de que no tenemos todavía con que premiar los tales de primer orden, como se premian en las ciudades de Europa. ${ }^{13}$

El arribo de cantantes y músicos se reiteró en agosto del mismo año. Al tiempo que Pablo Rosquellas y Miguel Vacani se incorporaron definitivamente a la compañía del teatro Coliseo Provisional, la prensa se refirió al arribo de José Troncarelli y Julieta y Carlota Anselmi, todos italianos. ${ }^{14}$ En relación a estos dos últimos, debe señalarse que el ingreso de Julieta estuvo a cargo de Troncarelli, quien realizó un contrato especial para que ella y su hija Carlota arribaran y se instalaran en Buenos Aires bajo su protección. ${ }^{15}$ En la referencia a este segundo viaje, la prensa ya no remitió a la intervención del gobierno rivadaviano, sino que destacó que a partir de entonces primaba la intención personal de Rosquellas de formar una compañía lírica y,consecuentemente, de establecerse como empresario teatral. En este sentido,

13 (16 de marzo de 1823). El Centinela, Buenos Aires, núm. 33.

14 "Es con sumo placer que podemos anunciar al público que se han incorporado en la compañía, los profesores Rosquellas y Vacani, y la joven Anselmi bajo condiciones que concilia sus intereses individuales con los del Asentista (...)". (19 de agosto de 1823). El Centinela, Buenos Aires, núm. 56. Sobre el arribo de cantantes e instrumentistas italianos a Buenos Aires durante la década de 1820 véase: Guillamon (2015a, 2015b y 2017: 37).

15 Cabe señalar que los vínculos entre los cantantes y músicos no carecían de tensiones. En 1823 Troncarelli acusó a Anselmi de incumplir el contrato en el cual se establecían las pautas de trabajo de la cantante. Dicho juicio se encuentra en: Archivo General de la Nación, Buenos Aires (en adelante AGN), Tribunal Civil, Legajo T - 5 1823/1824. En este sentido, debe remarcarse que a diferencia de Rosquellas, quien acusaría al asentista de incumplir un contrato verbal, los contratos de cantantes femeninas fueron siempre realizados de forma escrita y en italiano, por lo cual eran ellas mismas las responsables de traducirlos a fin de realizar la defensa de las acusaciones que se les imputaban. Al respecto de las trayectorias femeninas y de tempranas formas de agencia respecto de los proyectos personales, véase: Guillamon (2019) 
debe resaltarse su experiencia previa como mediador de la disputa que enfrentó a la Compañía Lírica -integrada por cantantes- y la Compañía Nacional -compuesta por actores- por la apropiación del asiento del Teatro de Río de Janeiro (Almeida Cardoso, 2011). Al tiempo que le permitió ganar legitimidad en su propio círculo de músicos allegados, lo dotó de recursos y saberes que posteriormente desplegaría en Buenos Aires. Específicamente, estas vivencias le posibilitaron erigirse en el principal referente del género en el escenario teatral en Buenos Aires, como así también en el intermediario entre el Teatro, los cantantes y el poder político.

Más allá de ciertos casos específicos de vinculación, a partir de mediados de 1823, Rosquellas comenzó a dar cuerpo a una red de músicos italianos que conformarían la Compañía Lírica, y le posibilitarían disputar el asiento del Coliseo y transformarse en asentista y empresario del Teatro. Al tiempo que dicha red dinamizó y fortaleció el escenario porteño, el carácter itinerante de los músicos y cantantes constituyó una de las causas del abrupto declive de actividades líricas en el Teatro. El cuadro que se presenta a continuación pretende dar cuenta de la capacidad de las vinculaciones y la consecuente red que estableció Rosquellas. Pero, al mismo tiempo, las trayectorias de músicos y cantantes evidencian que Río de Janeiro, Montevideo, Santiago de Chile, Valparaíso y Buenos Aires constituyeron centros urbanos que impulsaron una fuerte actividad artística, constituyéndose así como polos de atracción para el desarrollo profesional musical (Farías Vazquez, 2003; Mugayar Kühl, 2003).

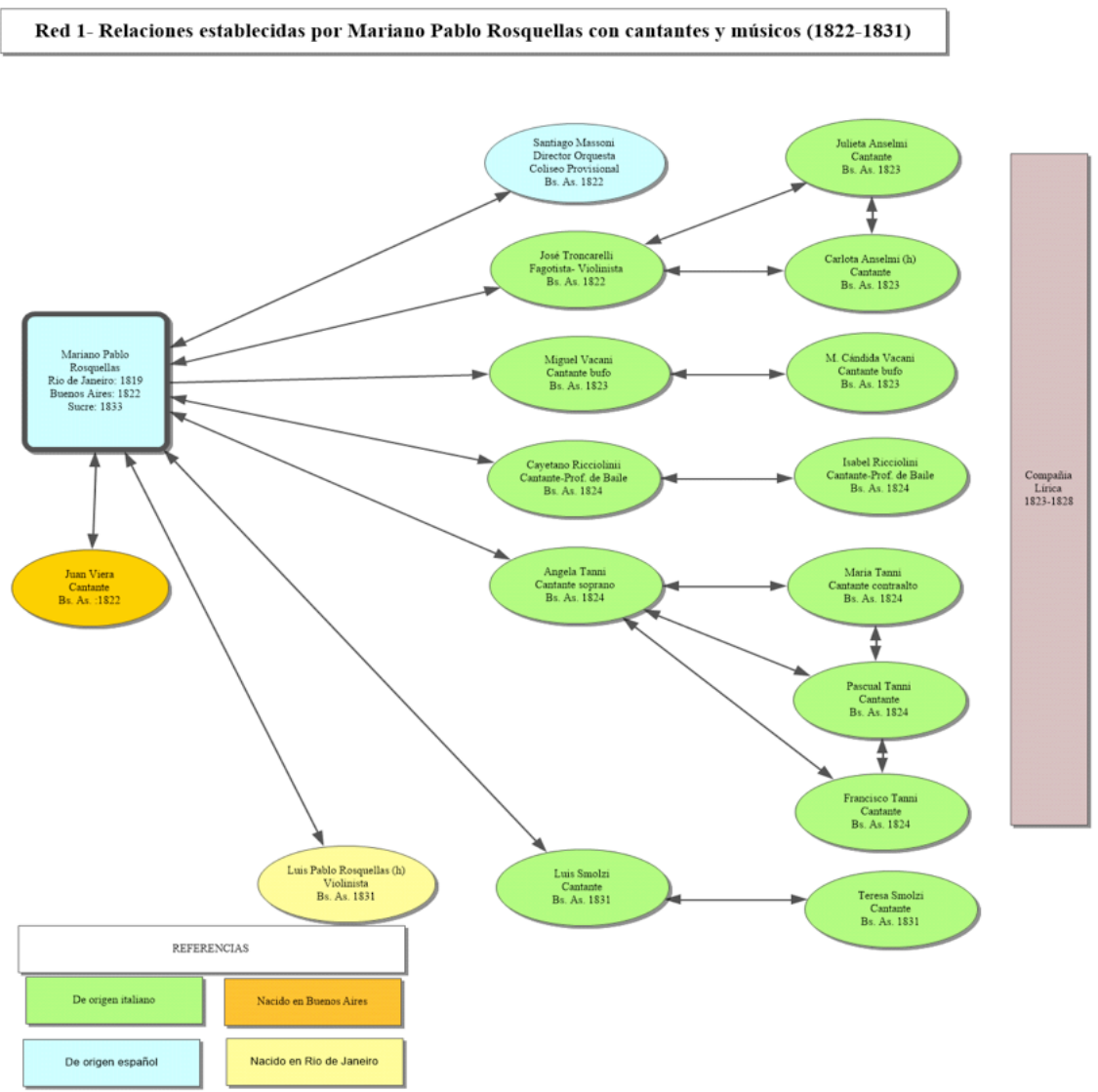

Fuente: Elaboración propia a partir de la sistematización de información proveniente de prensa, crónicas y memorias, Actas de Policía y expedientes judiciales del Tribunal de Justicia durante el período 1821-1831. 
Seguida de la irrupción de nuevos cantantes de origen italiano bajo la égida de Pablo Rosquellas, comenzó a promocionarse sistemáticamente en la prensa porteña la programación de las funciones a desarrollarse. En ellas, se explicitaron las formas que se ejecutarían y los compositores de las mismas, al tiempo que advirtieron que las funciones se llevarían a cabo en beneficio de determinados cantantes o instrumentistas de la compañía. El formato de funciones a beneficio nos permite inferir tanto la inicial inestabilidad de la compañía, como la inexistencia de ayuda económica por parte del Estado provincial. ${ }^{16}$

Asimismo, los cambios en la programación y la consolidación del Teatro Coliseo Provisional como principal espacio musical, deben ser analizados en relación a dos situaciones que los posibilitaron: por un lado, las acciones que desplegó Rosquellas a fin de convertirse en empresario teatral; y, por otro, el arribo de la prima donna Angela Tani, cantante italiana que estuvo bajo su égida hasta que formó su propia compañía lírica. ${ }^{17}$ Respecto de lo primero, en marzo de 1824 , Pablo Rosquellas inició un juicio contra el asentista e impugnó -exitosamente- su contrato. En agosto del mismo año, accionaría frente a la Policía para convertirse en asentista del teatro con el propósito de realizar dos funciones mensuales, prometiendo garantizar un amplio repertorio lírico. ${ }^{18}$

Sin embargo, debe señalarse que, más allá de las intenciones de Rosquellas de poder liberarse de las obligaciones contraídas con el asentista, la prensa ya había señalado y criticado la falta de funciones líricas. No sólo se adujo que el asentista -que en aquel momento era Antonio Pereyra- debería devolver el dinero de las entradas dada la carencia de la programación anunciada, sino que se señaló que:

(...) le corresponderá tan solo al gobierno (que ciertamente no se habría deshecho de la casa de comedias sino con intención de asegurar al público un entretenimiento racional) cuidar, no solo que se restablezca la cuota y se quite la lotería, sino también que la casa de comedias de su propiedad, al acabarse la actual contrata en el mes de Noviembre, pasé a manos que sepan que es el teatro; y sobre todo lo que se debe al público. ${ }^{19}$

Pasados unos meses, La Gaceta Mercantil se hizo eco de la resolución del conflicto; anunció que dicha petición se había concretado y que, "A consecuencia de haber permitido el Superior de Gobierno la exhibición de dos funciones mensuales de música vocal e instrumental al profesor D. Pablo Rosquellas”, comenzaría la

16 Según Roger Allier (2008: 54-55), esta forma de anuncio, originado hacia fines del siglo XVIII europeo, conformó una estrategia a fin de paliar la inseguridad económica de los principales cantantes.

17 “El respetable profesor Rosquellas, su excelente discípula Angelita, y la hermana María, han sido contratados para el canto: también parece haberlo sido para la orquesta el distinguido Massoni (...) La quemazón total del gran teatro del Janeiro, que parece haber acontecido el 25 del pasado hallándose en el S.M.I. le presenta al Asentista la oportunidad de recuperar al gran Vacani". (28 de marzo de 1824). El Argos de Buenos Aires, Buenos Aires, núm. 32.

18 (12 de agosto de 1824). El Argos de Buenos Aires, Buenos Aires, núm. 62.

19 (1 de agosto de 1824). El Argos de Buenos Aires, Buenos Aires, núm. 59. 
temporada lírica. ${ }^{20}$ A partir de este momento -en el cual las funciones quedaron a cargo de dicho músico-, comenzó a promocionarse la programación, que predominó hasta 1828.

Tal como hemos advertido, es recurrente señalar que en 1825 se estrenó El barbero de Sevilla en el Coliseo. Sin embargo, no se ha indagado acerca de las razones que habilitaron su representación completa. Respecto de ello, es interesante resaltar que en julio de dicho año se celebró un contrato entre Pablo Rosquellas -en tanto representante de la Sociedad de los Tres Amigos- y el gobierno, en el cual se explicitaba que el músico actuaría como asentista. ${ }^{21}$ Desde dicha fecha, su compañía gozó de estabilidad respecto de su conformación, pero también en lo referido a la periodicidad y contenido de sus presentaciones. ${ }^{22}$

En lugar de diversificarse, la programación se homogeneizó en torno a un sólo género: la ópera. Como venimos exponiendo, la elección se fundamentó en la familiaridad de los cantantes arribados a Buenos Aires con dicho género, como así también por la preferencia del público porteño por escenas musicales -música, canto y teatro-, tales como la tonadilla y el sainete. En consecuencia, tal como postuló el programa modernizador del gobierno rivadaviano, la transformación del gusto musical se estableció en referencia a un cuerpo de obras investidas de legitimidad y estatus musical a nivel global, haciendo que el Teatro sólo se identificase con dicho género. Asimismo, la prensa porteña dedicó extensos apartados a propaganda y crítica musical, en los cuales se constituyó una doble acepción de buen gusto: una relacionada las pautas de civilidad, que se esperaba que se desarrollasen hacia el interior del Coliseo Provisional, y otra vinculada a la práctica y escucha musical en sí misma.

Aunque aquí no nos extenderemos sobre la especificidad del repertorio lírico ejecutado en el Teatro, debemos destacar que entre 1825 y 1828 se estrenaron más de 20 óperas -15 de éstas pertenecientes G. Rossini-, se desarrollaron hasta 40 funciones de óperas completas en una temporada, y una misma ópera se repitió un total de 35 veces durante esos tres años. Tal como evidencian los gráficos a continuación, si se observa la cantidad de óperas representadas en su totalidad, se presenta una relativa paridad entre serias -semiserias, dramas jocosos y melodramas- y buffas -se incluye aquí la ópera comique-, aunque el porcentaje varía notablemente al tomar como variable el número de repeticiones. Mientras que en el primer caso la mínima y máxima osciló entre una y once repeticiones, el segundo estilo llegó a reproducirse -como en el caso de El barbero- hasta treinta y ocho veces. A excepción de Don Giovanni, todas las óperas que fueron puestas en escena de forma completa más de cinco veces -independientemente de su estilo-, correspondían a G. Rossini. ${ }^{23}$

20 (3 de septiembre de 1824). La Gaceta Mercantil, Buenos Aires, núm. 265.

21 "CONTRATA celebrada entre el profesor D. Pablo Rosquellas Director de la Compañía de los Tres Amigos, y el Superior de Gobierno, comprándole la acción del Coliseo en la cantidad de diez mil pesos" Índice del Archivo del Departamento General de Policía, 30 de septiembre de 1825, N 40, Libro XII.

22 Al respecto, véase: Guillamon (2017)

23 Al respecto véase: Guillamon (2015a) 


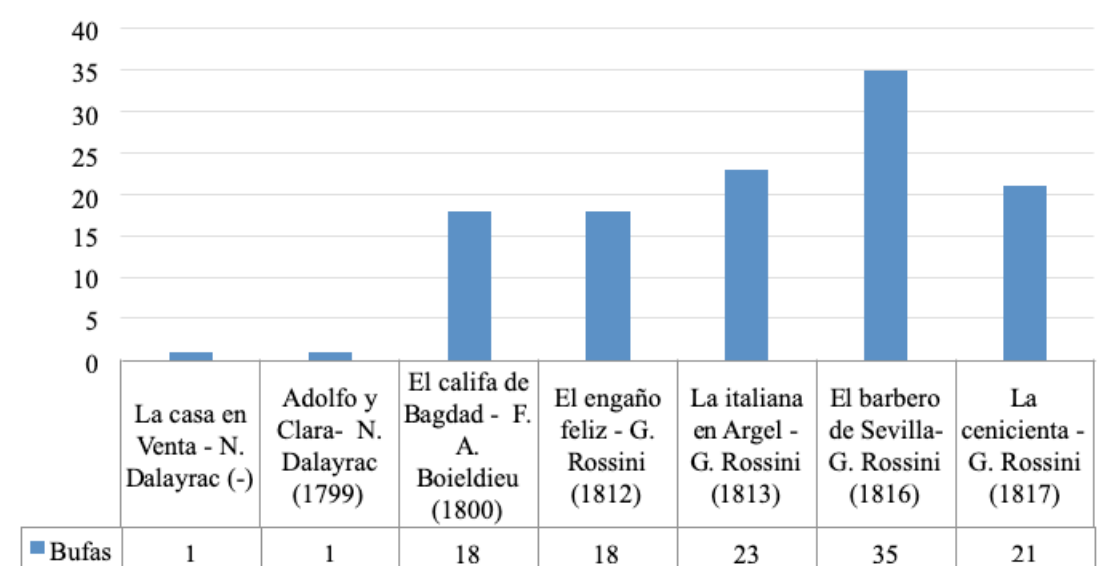

Gráfico 1. Cantidad de repeticiones de óperas buffas durante 1825-1828. Fuente: Elaboración propia a partir de Guillamon (2015a)

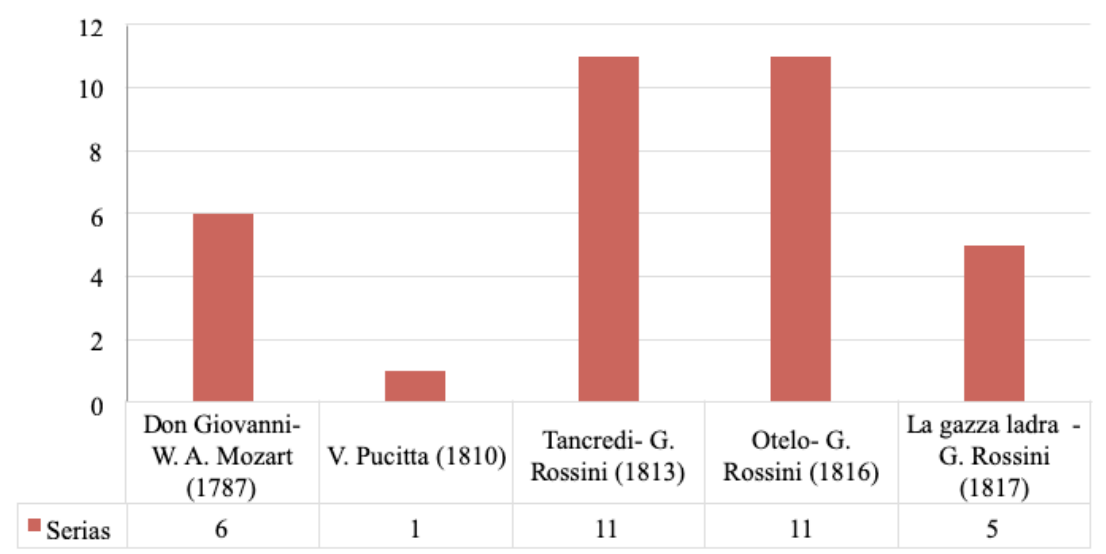

Gráfico 2. Cantidad de repeticiones de óperas serias durante 1825-1828. Fuente: Idem Gráfico 1.

En este sentido, hasta 1825 predominaron los conciertos de tipo misceláneo en tanto que patrón básico en la programación: piezas vocales e instrumentales intercaladas. Sin embargo, esta diversidad no fue sinónimo de heterogeneidad, dado que tuvo un formato constante. En los dos primeros años (1821-1823), se constata no sólo la alternancia entre el canto y las piezas instrumentales sino que, casi siempre, se inauguró el concierto con una obertura o sinfonía, formas musicales que dan inicio a la ópera. Si bien durante 1823-1825, el patrón de miscelánea continuó rigiendo los conciertos, éste se basó únicamente en las formas líricas constitutivas de la ópera. A partir de 1826 se evidenció una paridad entre la cantidad de funciones desarrolladas y el número de óperas representadas. 


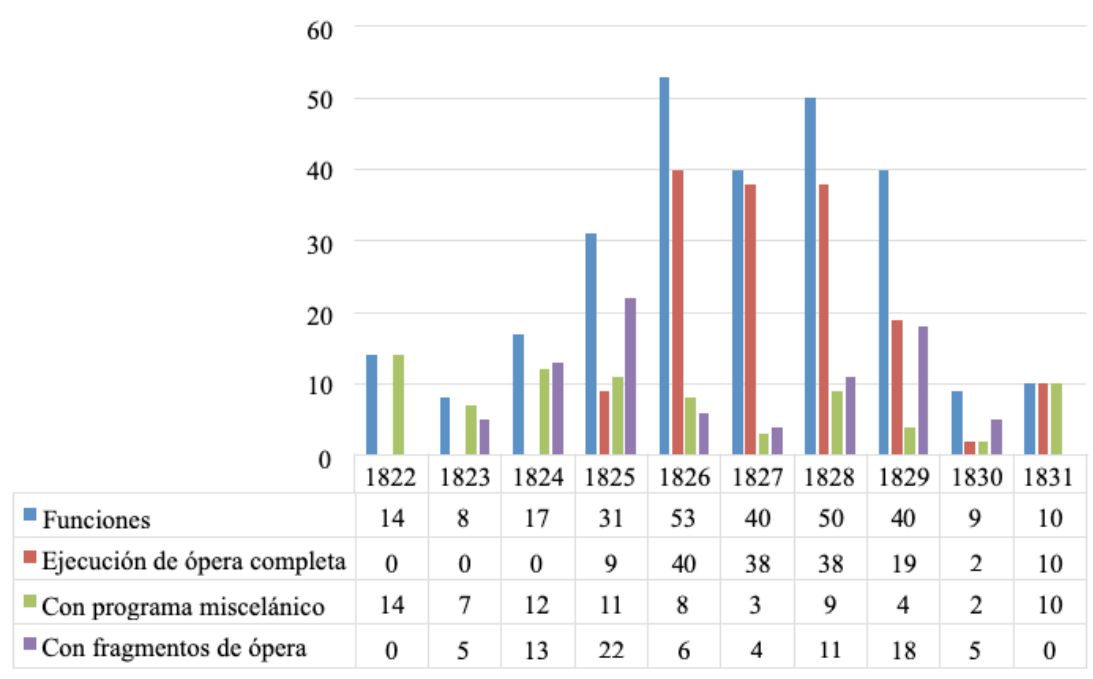

Gráfico 3. Programación en las funciones musicales desarolladas en el Coliseo Provisional entre 1822-1831. Fuente: Elaboración propia a partir de la sistematización de información proveniente de prensa edita durante el período 1821-1831.

Retomando el interrogante en torno al éxito de la ópera, la respuesta puede basarse en los aspectos característicos de la ópera italiana: el predominio de la música sobre la armonía en las arias y la proximidad del idioma español al italiano. La voz -que adquiere en ese tipo de concierto una función verbal pero también emocional- sería así asequible al público porteño y, al mismo tiempo, conocida, dada la afinidad a las tonadillas y sainetes

Por otro lado, también las estructuras argumentales de las principales óperas rossinianas pueden explicar su éxito en el escenario porteño y la consecuente afición del público. ${ }^{24}$ Retomando los gráficos 1 y 2, las óperas más representadas por la compañía de Rosquellas fueron aquellas pertenecientes a G. Rossini, a saber: por un lado, las buffas El engaño feliz (Venecia, 1812), La italiana en Argel (Venecia, 1813), El barbero de Sevilla (Roma, 1816), La Cenicienta (Roma, 1816); pero también las serias Tancredi (Venecia, 1813) y Otelo (Nápoles, 1816). Indistintamente, estas diferenciaciones comparten características en común: sus libretos narran historias de amor. ${ }^{25}$ Respecto de la especificidad narrativa de la ópera buffa, cabe señalar dos aspectos: por un lado, se incorporó un tono sentimental a las historias, aunque no excesivamente trágico; por otro, las óperas comenzaron a reflejar aspectos de la sociedad, matizándolos con costados cómicos y burlescos.

No obstante la particularidad de los libretos originales -específicamente de aquellos de autoría de Rossini-, se debe agregar que la prensa hizo referencia a la adaptación que habría realizado Rosquellas de ciertas óperas a fin de que el público no las

24 La importancia del análisis de los libretos de ópera, de la construcción teatral de los personajes y su consecuente desarrollo musical, fue señalado recientemente por Martha Nussbaum. Particularmente, en su exhaustivo trabajo sobre de Las bodas de Fígaro, la filósofa demostró que el abordaje de las relaciones de amor y de las emociones en las óperas constituye un importante vector para indagar en torno a ideas estéticas pero, por sobre ello, sobre la circulación de conceptos y prácticas políticas en el público aficionado. Nussbaum (2014).

25 Un análisis preliminar de esta problemática se realizó en Guillamon (2017: 41) y (2018: 195) 
reprobara, tal como había sucedido con Don Giovanni, de W. A. Mozart. Específicamente, se destacó la modificación de aquellas de carácter serio, tales como Otello, de Rossini, y la Vestale, de Pucitta, alejadas de la dinámica propia de las óperas cómicas. En referencia a esta última, la única ópera representada con un marcado carácter neoclásico, se señaló que "La Vestale, la insípida Vestale, como ha sido llamada, que en su primera representación aquí hace unos mesas ha sido un fracaso, ha sido tan podado y alterado que ahora se convierte en una ópera muy agradable”. ${ }^{26}$

Así, en 1828 se cristalizó un proceso que intentó consolidar un repertorio canónico con géneros otrora difundidos pero, por sobre todo, hegemónicos en las principales ciudades de Europa. Consecuencia del accionar de Pablo Rosquellas y de la insistente promoción y crítica realizada por la prensa, el gusto de la elite porteña se estableció en relación a un cuerpo de obras clásicas investidas con el estatus de legitimidad. Los conciertos basados en clásicos rossinianos se convirtieron en la cultura elevada pero también en vanguardia musical, en un “(...) torrente de la moda que parece haber determinado que debe desaparecer toda música de ópera que no sea la de Rossini. Incluso la pobre Vestale está condenada a morar en la oscuridad". ${ }^{27}$

El lugar periférico de la ciudad de Buenos Aires y la precocidad del fenómeno permiten poner en tensión y discutir aquellos trabajos que, a partir de un análisis centrado en Europa -más específicamente en París-, sitúan a 1830 como la década de auge y consolidación de dicho género (Osterhammel, 2015: 5-9). En este sentido, el análisis de la ciudad porteña da cuenta de un doble movimiento. Por un lado, muestra que Buenos Aires se integró tempranamente a lo que puede denominarse como una "cultura artística global", desarrollando una sociabilidad de alta cultura que excedió las fronteras de la ciudad y se vinculó con las experiencias de las capitales europeas. Pero, al mismo tiempo, si ponemos el foco de atención en el proceso consolidación de una cultura musical vinculada a la ópera, se advierte que la forma de desarrollarse y arraigarse posee una dinámica específica, propia de una capital otrora virreinal, de carácter marginal, a una ciudad que pujará por transformarse en la Atenea del Plata (Gallo, 2012: 104)

El esplendor de la ópera continuó hasta 1829, año en el cual las funciones disminuyeron de forma acelerada. Entre los motivos de esa caída, emerge en primer lugar una explicación política, que encuentra en la finalización de la denominada "feliz experiencia" la cancelación de un conjunto de políticas que impulsaban la cultura musical y que, en última instancia, habilitaban y sustentaban la escena musical erigida por Pablo Rosquellas y su compañía lírica. No obstante esta coyuntura política, en el apartado que se desarrolla a continuación se busca dar cuenta de cómo la situación económica personal del músico -específicamente la acumulación de deudas a título personal, como así también

26 (24 de enero de 1829). The British Packet and Argentine News, Buenos Aires, núm. 129. Al respecto véase Guillamon (2017: 42)

27 (16 de agosto de 1828). The British Packet and Argentine News, Buenos Aires, núm. 106. 
las malas inversiones que había realizado en el marco de la crisis económica de fines de la década de 1820- fue una dimensión decisiva para el progresivo declive de la ópera en Buenos Aires.

\section{Accionar para disputar: Espacios culturales, roles empresariales y estrategias teatrales desplegados por Rosquellas.}

En agosto de 1824, El Argos de Buenos Aires manifestó que el músico Pablo Rosquellas había iniciado un juicio contra el asentista en el que pedía al gobierno poder alquilar el Teatro Coliseo Provisional, específicamente por esa temporada. ${ }^{28} \mathrm{El}$ juicio contra el asentista Antonio Pereyra residió en impugnar un contrato verbal en el cual Rosquellas se comprometía a efectuar dos funciones mensuales, con un sueldo de 200 pesos, por entonces la moneda corriente en Buenos Aires. No sólo consideró bajo el sueldo propuesto, sino que manifestó que no estaba dispuesto a trabajar bajo la dirección de un asentista que no fuese él mismo. De forma paralela, la prensa, además de señalar las intenciones de Rosquellas de liberarse de las obligaciones contraídas con el asentista, ya había destacado y criticado la falta de funciones líricas. ${ }^{29}$

Si bien este juicio no fue descrito explícitamente por las Actas de Policía, dado que tuvo curso enel Tribunal Civil, se encuentran irregularidades respecto de los contratos realizados mediante el Departamento de Policía durante 1824. El primero de ellos, fue realizado en mayo de ese año, en plena contienda judicial entre el músico y el asentista, por voluntad del propio Pereyra, a fin de regular su labor. Compuesto por 12 extensos artículos, el contrato refería a obligaciones respecto del número de funciones, pagos y contratos a músicos y actores y, por sobre todo, a las mejoras que debía realizar en la colección de piezas teatrales, de canto y música. ${ }^{30}$ Así, el reglamento fue una evidente consecuencia de las irregularidades contractuales que habían dado lugar a la disputa entre ambos.

Aunque en la contrata de Pereyra se advertía que las obligaciones se extenderían por dieciocho meses, el 17 de septiembre de 1824 Pablo Rosquellas elevó, a través de la Policía, una nota a Rivadavia -aunque éste se encontraba en el exterior- y manifestó su intención de comprar el asiento del teatro. ${ }^{31}$ Remitiéndose a otro acta que habría elevado en agosto y de la cual no había obtenido respuesta, volvió a reiterar el pedido, acompañado de un largo programa de reformas a efectuarse por la "Sociedad de los Tres Amigos", asociación también compuesta por Julián Moreno y Gabriel Munilla. La concreción del asiento se reflejó en la programación

28 (12 de agosto de 1824). El Argos de Buenos Aires, Buenos Aires, núm. 62.

29 (4 de agosto de 1824). El Argos de Buenos Aires, Buenos Aires, núm. 59.

30 AGN, Departamento General de Policía. Libro 9, N 104, 12 de Mayo de 1824. Sala X, Legajo 32-10-4.

31 AGN, Departamento General de Policía. Libro 12, N 177, con fecha de 18 de Julio de 1825. Sala X, Legajo 32-10-5. Se aclara que, tal como se dijo en el cuerpo del texto, la nota tiene fecha del 17 de septiembre de 1824. 
musical: hacia 1825 la actividad del Coliseo Provisional se orientó a la ópera buffa, género introducido principalmente por Rosquellas y su compañía lírica. ${ }^{32}$

No obstante, este abordaje debe complementarse con los juicios civiles que desplegó Rosquellas entre 1823 y 1824 para desvinculare del asentista del Teatro y, en consecuencia, convertirse en empresario del Coliseo Provisional. ${ }^{33}$ Además de iluminar en torno a las vinculaciones contractuales, permite aproximarse al universo social de lo que aquí denominamos como cultura musical. Con ello, queremos hacer hincapié en el hecho de que sus disputas evidencian la capacidad de Rosquellas de gestionar su propia carrera artística y accionar judicialmente en pos de que se respetara su propia labor. Asimismo, estas instancias -que devienen en una regulación y normativización del propio oficio del hacer música- nos permiten comenzar a indagar sobre el proceso de profesionalización de los músicos y cantantes.

Retomando los juicios que desarrolló Rosquellas, en el primero de éstos fundamentó el reclamo en un supuesto incumplimiento del contrato, acusando a Pereyra de haber concertado dicho pacto de modo oral, contradiciendo así el reglamento que él mismo había celebrado con la Policía, donde se advertía que todo tipo de arreglo debería ser realizado de forma escrita. En consecuencia, la disputa discurrió sobre la voluntad de Pereyra de obligar al músico a trabajar en todas las funciones que se dieran en el Coliseo, mientras que Rosquellas acusó al asentista de aprovecharse de una cláusula inexistente, para hacerlo cantar más de lo convenido. En este sentido, se advierte un elemento ausente en las actas de Policía: un error contractual, equivocación que el músico español utilizaría y moldearía según sus intereses.

Así lo expresaba el propio Pablo Rosquellas en el primer escrito que remitió al Juez:

\begin{abstract}
Hallandome al servicio del publico en el Teatro provisional de esta capital como Profesor de Canto por convenio con el asentista Don Juan Antonio Pereira sin formal contrata como está previsto en el art. $7^{\circ}$ de la que este celebro con la Policia, cuyo articulo textual dice que todas las contratas que el asentista celebrase con los actores han de ser visado por el Sr. Jefe del Departamento de Policía (....) ha resuelto que sin consultar mi deferencia como devio hacer en todos los anuncios para las funciones que han de exibirse; ha anunciado función para el día 25 . Cuando estoi decidido a no continuar en aquel egerscicio, supuesto que no se hallo resaltado por contrato expresado. ${ }^{34}$
\end{abstract}

Sin embargo, luego de iniciado el juicio, Rosquellas involucró a las hermanas Maria y Angela Tanni, por ese entonces bajo la égida del músico y también obligadas a trabajar en todas las funciones aun no habiendo estado esto estipulado en el contrato. Ante ello, Pereyra elevó un escrito en el que demandó a los cantantes por incumplimiento de contrato verbal, hecho que derivó en el juicio oral en el cual

32 Asimismo, la crónica Cinco años en Buenos Aires también refiere que en enero de 1825, luego de dos meses cerrado el Teatro a causa de reformas edilicias, se había reabierto la temporada de ópera bajo la dirección de Rosquellas (Love, 2014: 31)

33 AGN, Tribunal Civil, Legajo R 12-1824.

34 AGN, Tribunal Civil, Legajo R 12-1824. 
el empresario argumentó que "este serviría al teatro en la parte de canto por el sueldo mensual de doscientos pesos, sin determinarse numero de funciones, sino en que cantaría indefinidamente todas las veces que fuese necesario, y que por esta razón extendió el sueldo de las niñas Tanni a doscientos pesos cada una por mes" ${ }^{35}$ En contraparte, Rosquellas repuso que él "no cantaria en las funciones de tabla, pues ni con quatro cientos pesos mensuales que se le dieren, entraria a contratarme a dirección de un asentista, y que por consiguiente no puede conformarse en continuar cantando, y que reclama se declare absuelto del mismo (...)".36

A partir de esta instancia, se advierte que la disputa entre ambos se había iniciado antes de la contienda judicial, a saber, en el momento en que Pereyra había recurrido a la Policía a fin de dejar asentado el incumplimiento. Sin embargo, el Comisario -enunciado como a cargo de la Presidencia de las funciones teatrales- advirtió que al no haber respetado el artículo $7^{\circ}$, que obligaba a realizar de forma escrita los contratos, quedaba invalidado el reclamo. Derivado de ello, el Juez habilitó a Rosquellas a accionar para romper sus obligaciones.

En consecuencia, el cantante desplegó una serie de argumentos ligados a su propia labor musical y a experiencias previas para invalidar sus obligaciones. Esta estrategia evidencia no sólo el conocimiento que dicho músico poseían sobre la propia dinámica teatral, sino la voluntad de concebir su labor como una profesión, haciendo respetar sus derechos contractuales por considerarlos inválidos en relación a otros Teatros. Así, en primer lugar, Rosquellas impugnó el contrato no sólo por no estar escrito, sino

Por lo nosivo y perjudicial debía serle a su salud, como porque sería singularizarse contra la práctica general de los teatros, en donde los profesores de canto solo sirven a las funciones ordinarias, y en alguna otra extraordinaria de un objeto de publica plausividad; prescindiendo de otra razón muy esencial, qual es la de que en un teatro provisional que carece de vestuario como el nuestro, las doce onzas con que el asentista se persuadía pagarle exorbitantemente, no le serían suficientes a costear los trajes necesarios a presentarse con lucimiento en todas las funciones que estuviese en el interés del empresario resivir (...). ${ }^{37}$

Al momento de esbozar esta justificación, basada en la carencia de elementos que garantizaran el desarrollo de las funciones, Pereyra adujo que "estaba decidido a pasar al Janeiro a contratar actores de canto a su arbitrio", a lo que replico Rosquellas que "así como no accedería jamás a contratarse del modo que se pretendía celebraría que verificase su proyecto de pasar al janeiro para que supiera apreciarlo mas en otra ocasión". ${ }^{38}$ La intención de viajar hacia Brasil evidencia, por un lado, el hecho de que Río de Janeiro funcionó como un punto nodal a partir del cual, tanto como consecuencia del incendio del Teatro como por la propia ida de Rosquellas, los músicos italianos arribaron a Buenos Aires. Asimismo, el

35 AGN, Tribunal Civil, Legajo R 12-1824.

36 AGN, Tribunal Civil, Legajo R 12-1824.

37 AGN, Tribunal Civil, Legajo R 12-1824.

38 AGN, Tribunal Civil, Legajo R 12-1824. 
supuesto viaje se vincula con aquello que previamente enunciamos como un stock de esquemas de acción derivados, a su vez, de sus experiencias musicales, pero también socio-políticas previas. En este sentido, la respuesta de Rosquellas muestra que era éste el que mantenía allí estrechos contactos, quedando Pereyra por fuera de dicho circuito y siendo su propuesta sólo una amenaza estéril.

Sin embargo, el empresario volvió a dirigirse al Juez para desplegar un nuevo argumento en torno al necesario cumplimiento del contrato: el músico no sólo estaba obligado a trabajar para Pereyra sino

con el publico, a quien a virtud del contrato que hemos celebrado, le he prometido que este cantaría en todas las funciones teatrales, de modo que el dispensarlo de estas obligaciones sería cargar sobre mi una responsabilidad que no puedo satisfacer, pues no hay en el país quien pueda sustituirlo, y por consiguiente quien me desempeñe de las que he contraído con el público. ${ }^{39}$

Sin embargo, la adulación duró poco. En los escritos sucesivos, Pereyra atacó a Rosquellas por considerar inconcebible la comparación del Coliseo Provisional con otros Teatros europeos, dado que "la costumbre de otros teatros no puede tener aplicación al nuestro, en razón de que toda costumbre no tiene mas el imperio que en el país en que se adoptan, asi que sería muy ridículo querer aplicar al teatro Coliseo Provisional costumbre que siguen, por ejemplo, en el teatro de Paris". ${ }^{40}$

A ello se agregaría otro supuesto, a saber, la voluntad de Pablo Rosquellas de desligarse del contrato para convertirse él mismo en empresario teatral. Por lo tanto, no sólo era necesaria la impugnación, sino la desacreditación pública de Pereyra. Remitiéndonos al marco temporal del expediente, el juicio se desarrolló al mismo tiempo que, como se ha señalado previamente, la prensa advirtió sobre la carencia de funciones líricas y la inestabilidad teatral en general. Así, a la denuncia de un supuesto accionar arbitrario del Juez y del Departamento de Policía a favor del músico español, Pereyra adujo que todos los argumentos esgrimidos sólo eran parte una artimaña para acceder al asiento. El último escrito fue, en base a estas ideas, el que más violentamente interpeló a Rosquellas e intentó desacreditar su capacidad como cantante:

Dice que no pudo contratarse del modo que yo he indicado por que le seria mui nosivo a su salud, y advierta $V$. que ese mismo hombre que se manifiesta tan celoso de su salud, no ha dejado de cantar en una sola de las funciones teatrales de donde, pues, le ha nacido ese temor por su salud?? De que quiera faltar a sus compromisos, tiene aspiraciones a ser empresario, y he ahí la razón de todos esos procedimientos tan indebidos como maliciosos. Otra deduccion hay que hacer del asierto anterior. Si Rosquellas ha cantado en todas las funciones que se han dado hasta ahora es precisamente por que se consideraba obligado a hacerlo, y no por gracia como ahora pretende persuadir. ${ }^{41}$

39 AGN, Tribunal Civil, Legajo R 12-1824.

40 AGN, Tribunal Civil, Legajo R 12-1824.

41 AGN, Tribunal Civil, Legajo R 12-1824. 
Luego de ello, Pereyra volvió a dirigirse al Juez, esta vez para acusarlo de rebeldía al no haber dado lugar a su acusación. A continuación, se volvió a copiar el artículo $7^{\circ}$ de la Policía y se pasó a dar el veredicto final: Pablo Rosquellas quedaba libre.

El recambio de asentista fue abordada por la prensa, en tanto advirtió que partir de la intervención de Rosquellas se inauguraría un período de auge teatral:

\begin{abstract}
Este establecimiento de recreo y de ejemplos de moral; en nuestro país, ha adolecido siempre de defectos que exigían reforma -tanto respecto a la no protección de las autoridades, cuanto a la falta física y moral de sus directores. La primera admite en parte disculpa por las circunstancias; mas la segunda, cimentada en el deseo de recoger frutos sin sembrar, ni preparar el terreno; ha sido y es imperdonable. Mas esto no es del caso; pues que ya desapareció aquel tiempo, para que le suceda otro, bastante agradable y deseado de los que no ignoran la utilidad del Teatro, y los bienes que produce en la sociedad. Los nuevos empresarios hacen actualmente (de un modo práctico) conocer esta verdad... Ellos deben tener la satisfacción de que sus esfuerzos no son desconocidos. ${ }^{42}$
\end{abstract}

En su contrato, Rosquellas afirmó -en forma similar a lo que había propuesto Pereyra-, que no omitiría esfuerzo alguno "hasta conseguir su representación en el teatro de Buenos Aires de las grandes composiciones que ya hoy decoran los principales de Europa". ${ }^{33}$ Para concretar dicho objetivo, había adelantado fondos a España para obtener, hacia fines de 1825, al menos treinta óperas con su correspondiente música y letras en castellano, francés e inglés. También se comprometió a formar en "el decoro y la sutileza" a las cantantes líricas Angela y Maria Tani, recientemente convocadas por el propio Rosquellas desde Río de Janeiro y que posteriormente se convertirían en las prima donna de la compañía. La voluntad de complejizar la programación, contratar nuevos cantantes y formar una compañía lírica también devendría en rédito para el gobierno, en tanto "habría tantos más espectadores cuanto más robustecida se halle la empresa". ${ }^{44}$ En síntesis: todas las acciones propuestas, además de buscar persuadir al poder político, evidencian el conjunto de responsabilidades que debería cumplir un empresario teatral de principios del siglo XIX.

Si bien podría pensarse que la oferta formaba parte de la intención de lograr la contrata, si se indaga en el repertorio que su compañía ofreció en Rio de Janeiro desde 1819 hasta 1823, se verifica que sólo tres de las más de veinte óperas realizadas en Buenos Aires habían sido presentadas previamente. Por otra parte, la promoción de la programación del Teatro que realizó la prensa es coincidente con el contrato ejecutado con Pablo Rosquellas, ya que a partir de 1824 predominaron las óperas buffas al tiempo que desaparecieron la tonadilla y el sainete. Mientras que la ópera estuvo asociada al buen gusto, las formas lírico-teatrales españolas -particularmente la tonadilla y el sainete- fueron

42 (17 de enero de 1825). El Americano Imparcial, Buenos Aires, núm. 1.

43 AGN, Departamento General de Policía. Libro 12, N 177, 18 de Julio de 1825. Sala X, Legajo 32-10-5.

44 AGN, Departamento General de Policía. Libro 12, N 177, 18 de Julio de 1825. Sala X, Legajo 32-10-5. 
condenadas en la prensa por su nula calidad estética y musical y, por sobre ello, por ser representativas de un pasado ligado al atraso y a la subordinación de la Corona española.

Asimismo, es necesario resaltar la constante interpelación que Rosquellas realizó al gobierno, ya que en su contrato señaló que su proyecto teatral estaba en estrecha relación con el ideario modernizador e ilustrado que pretendía concretar el poder político. Así, en primer lugar, intentó persuadir sobre la necesidad de su protección al referirse al Teatro argumentó que:

Los progresos que este puede hacer bajo un gobierno sabio y liberal y los bienes que puede y debe proporcionar al público- los espectáculos conciernen a las grandes poblaciones, y en uno como la nuestra donde absolutamente se encuentra otra diversión poca. Esta debe ser de un sumo interés conservarla, fomentarla y adelantarla. ${ }^{45}$

Así, toda mejora en la administración del teatro se reflejaría necesariamente -siguiendo la propuesta del contrato- en la mejora de la sociedad porteña dado que:

una propuesta que tendiendo directamente en beneficio de la ilustración y engrandecimiento de este País, sus resultados sean realizables y en bien de la comunidad. A este efecto los subscriptos fuertemente interesados que este Pueblo figure en el rol digno de su actual administración, de su siglo y las disposiciones de sus habitantes (...... ${ }^{46}$

Pero no sólo se elogió al ideario político del gobierno, sino que también la Sociedad de los Tres Amigos -específicamente Rosquellas en nombre de ésta- discurrió sobre el contexto más general que atravesaba Buenos Aires. Así lo argumentaron en un escrito en el que rechazaban que el gobierno -y más específicamente la Secretaría de Hacienda-, luego de dos años de realizado el contrato, pudiese exigir nuevamente una cuota de alquiler, aun habiendo comprado la Sociedad todas las acciones del Gobierno. En consecuencia,

\footnotetext{
Últimamente en países como los nuestros, sugetos a oscilaciones donde los Gobiernos nacen, se forman y se destruyen, aquel artículo puede producir males y gastos a la Sociedad de los Tres Amigos. Si desgraciadamente sucediera que cambiase la administración y en lugar de un gobierno justo y liberal se instituyere alguna facción, bien podría suceder que la clausula (...) se glosase arbitrariamente y al termino de los años se procesa y sea esa contribución sobre el Coliseo incapaz de cubrirse sin una bancarrota impuesta a la Sociedad. ${ }^{47}$
}

La reflexión sobre el hecho de que toda inestabilidad política o coyuntura negativa devendría en pérdidas para el ámbito teatral, lejos de ser una premisa infundada, fue el fundamento del pedido de moratoria que Pablo Rosquellas realizó a sus acreedores mediante el Tribunal Civil. Cabe señalar, tal como advertimos

45 AGN, Departamento General de Policía. Libro 12, N 177, 18 de Julio de 1825. Sala X, Legajo 32-10-5. 46 AGN, Departamento General de Policía. Libro 12, N 177, 18 de Julio de 1825. Sala X, Legajo 32-10-5. 
previamente, que la quiebra del empresario se situó en el desarrollo de una fuerte crisis económica en Buenos Aires, en la cual confluyeron un conjunto de problemas: el inicio de la guerra con Brasil, la caída de los mercados de Londres y la consecuente crisis financiera institucional que derivó en un proceso inflacionario local. En ese marco, el poder adquisitivo se desplomó, afectando a asalariados, pero también -y particularmente en lo que a nuestro estudio se refiere- a muchos empresarios, que debieron afrontar un desajuste entre el valor de los bienes y las deudas, situación que devino en bancarrota (Djenderedjian, 2016: 118-119). La exposición desarrollada para lograr la moratoria -o más bien la condonación de las deudas- versó sobre dos ejes: la respetabilidad pública de Pablo Rosquellas y la caracterización que hizo de su persona, en tanto víctima de la inestabilidad económica que le impedía superar la situación de quebranto comercial. ${ }^{48}$

Sobrecogido de infortunios que, aunque frecuentes en la vida, amargan la existencia del hombre de honor, me veo en la precisa, bien que dura necesidad de implorar la benevolencia de personas tan respetables que fueron prontas a darme una mano $\mathrm{y}$ acompañarme para abrazarme del fracaso experimentado en octubre de 1827 y me habría seguramente repuesto de la funesta si en marzo de 1828 no hubiese renovado heridas que iban ya cicatrizando. Con todo no me arredré, sacrifiqué cuanto poseía a llenar los compromisos que resultaran de mis transacciones en 1827 (...), las pérdidas inevitables que me causó el falso anuncio de una paz que abatió los valores sobre esta plaza y que produjo la ruina de la casa de comercio mas fuerte, accidente que me obligo a tomar sumas de crédito bajo el crecido interés de coste con hipoteca de valor en alhajas que formaban los restos de mi fortuna. ${ }^{49}$

Sin embargo, las vicisitudes personales no fueron un obstáculo para que la prensa siguiera refiriéndose a Rosquellas, aunque ahora sólo fuese para narrar los viajes que había realizado a Rio de Janeiro y a Montevideo entre los años 1830 a 1833, a fin de brindar breves funciones de ópera. Si bien durante 1831 Pablo Rosquellas había regresado a Buenos Aires y se había presentado nuevamente en el escenario porteño, tanto la ópera como así también toda actividad lírica desarrollada en el Coliseo, se habían convertido en hechos del pasado. Por un lado, su hijo, Pablito Rosquellas realizó varias presentaciones de carácter miscelánico en el Coliseo. Si bien se destacó su capacidad para tocar el violín, antes que su virtuosismo musical, su promoción estuvo justificada por su precocidad. ${ }^{50}$ Por otra parte, durante 1831 y hasta 1832, se presentó conjuntamente con Luis Smolzi y su esposa Teresa, y asimismo con la pareja francesa Martinier, primero en el Parque Argentino, y luego en el Coliseo Provisional. Finalmente, en 1833, Pablo Rosquellas publicó en La Gaceta su carta de despedida, en donde

48 Es menester señalar que en 1835, cuando la Gaceta Mercantil se refirió a la llegada a Inglaterra del violinista y otrora director de orquesta en el Coliseo Provisional Santiago Massoni, la biografía realizada no sólo hizo referencia a sus logros como músico sino también como empresario, más bien fallidos. Por ello, refirió a que después de su estadía en Chile, Massoni se dirigió a la India en donde, si bien hizo fortuna, la terminó perdiendo por la quiebra de la casa comercial donde tenía depositado sus fondos. (1 de agosto de 1834). La Gaceta Mercantil, Buenos Aires, núm. 3360.

49 “Manifiesto de Pablo Rosquellas a sus acreedores”. AGN, Tribunal Comercial. Legajo R-305 (1831)

50 Al respecto, véase: (19 de marzo de 1831). La Gaceta Mercantil, Buenos Aires, núm. 2147 y (24 de noviembre de 1831). La Gaceta Mercantil, Buenos Aires, núm. 2342. 
agradeció el apoyo dado por sus amigos y por el público, y asegurándoles “(...) que siempre conservará de todos los mejores recuerdos y el afecto sincero que les ha profesado". ${ }^{51}$

Las extensas reseñas sobre las actuaciones habían desaparecido totalmente y, en su lugar, volvieron a promocionarse detalladamente los conciertos miscelánicos, tal como había sucedido en 1821 y 1822. Para 1833, cuando se esbozó la posibilidad de que las compañías de ópera asentadas en Montevideo pasaran por Buenos Aires previamente a su ida a Rio de Janeiro, el British Packet puso en duda la afición del público por la ópera, al afirmar que "incluso si fueran a visitar esta ciudad ahora, el furor respecto a ellos ha disminuido hasta ahora, que nos preguntamos si atraerían por cualquier largo período". ${ }^{2}$

\section{Conclusiones}

Al indagar en torno a la trayectoria de Pablo Rosquellas, emerge una escena musical que tuvo su epicentro de acción en el Teatro Coliseo Provisional de Buenos Aires. No obstante ello, las acciones que desplegó el músico dan cuenta de que dicha escena formó parte de un circuito cultural más amplio, en el cual confluyeron programaciones musicales, compañías líricas, saberes e ideas musicales, prácticas y estrategias de conformación del gusto. Asimismo, este artículo buscó mostrar cómo lo musical se constituyó como una actividad que excedió lo sonoro para abarcar otros espacios, prácticas y actores.

Los cursos de acción desarrollados por Rosquellas también muestran que el proceso de conformación de una cultura musical estrechamente vinculada a la afición por la ópera buffa fue consecuencia de su intervención -de forma conjunta a otros músicos- antes que de la voluntad modernizadora del gobierno rivadaviano. En este sentido, cabe destacar que sus experiencias y sus esquemas de acción previos, le permitieron vincularse en Buenos Aires con instituciones políticas, disputar intereses empresariales y regular su práctica musical.

Las dimensiones de análisis propuestas en el artículo buscaron dar cuenta de los cursos de acción que desplegó el actor en dos escenas vinculadas al ámbito de lo público: el Teatro y los espacios de regulación -Policía- y disputa -Tribunales Comercial y Civil- provinciales. Por sobre esto, la división persigue un objetivo más modesto, pero no por ello menos complejo: mostrar aquello de lo que fue capaz de hacer Rosquellas en Buenos Aires. Nos interesa hacer hincapié en esta cuestión, dado que su trayectoria en la ciudad estuvo trazada por la confrontación y la controversia con los otros, hayan sido estos particulares o instituciones estatales. Y fue en dichas instancias en donde desplegó narrativas que evidencian cómo las experiencias previas sobre el desarrollo de la misma

51 (25 de abril de 1833) La Gaceta Mercantil, Buenos Aires, núm. 2972.

52 (9 febrero 1833). The British Packet and Argentine News, Buenos Aires, núm. 338. 
profesión, como también la circulación y consecuente apropiación de saberes sobre la práctica misma, confluyeron en una "experiencia/noción propia" del quehacer musical.

Complejizar el manejo administrativo que Rosquellas realizó del Coliseo Provisional, nos conduce a otra dimensión que, aunque constitutiva del quehacer musical, supone un aspecto poco problematizado en relación a otras prácticas artísticas. En primer lugar, el supuesto de establecer el proceso de institucionalización del arte como la única variante que posibilita la profesionalización de sus actores (Zarlenga, 2014). A saber, en nuestro caso, el hecho de que los conservatorios y otros espacios, mediante la titulación, al tiempo que legitimaron la actividad artística, inauguraron fuentes laborales y erigieron a la música como una profesión (Zanolli Fabila, 1997; Caubet, 2017). Por el contrario, el recorrido aquí da cuenta de cómo ante la ausencia de dichos espacios, o frente a su efímera existencia, las relaciones que músicos y empresarios desarrollaron entre ellos mismos, como con el Estado provincial, habilitaron la conceptualización de la práctica musical no sólo como un oficio, sino como una profesión.

En este sentido, el Teatro Coliseo Provisional cobra centralidad para pensar el proceso de profesionalización de la labor musical. La trayectoria de Rosquellas muestra que, tanto los contratos de los empresarios, como también las disposiciones en torno a los derechos y obligaciones de los músicos, obligan a inscribir la profesionalización del arte, y de su relación con el Estado, en una historia a largo plazo (Aspell, 1992). Complementariamente, el análisis de las vinculaciones entre su trayectoria empresarial y la dinámica de la programación del Teatro nos invita a analizar cómo Buenos Aires transitó tempranamente un proceso de afición por la ópera buffa que -aunque con características inusitadas en relación al continente americano-, le permitió trascender las fronteras de la periferia e insertarse en una "cultura artística global".

En suma, este trabajo pretende ser el primero de una serie de investigaciones en las cuales buscamos poner el centro de atención en las acciones que desplegaron diversos actores musicales en la configuración de una cultura musical, en paralelo a la intervención política y a la regulación estatal. El análisis de la trayectoria de Rosquellas, y específicamente los cursos de acción que desarrolló en Buenos Aires, nos permiten afirmar que el proceso de conformación de una cultura musical fue la consecuencia de un entramado de acciones situadas de diversos actores musicales, quienes a su vez desarrollaron esos cursos de acción en distintas dimensiones dentro y fuera de lo musical: el Teatro y su infraestructura, el diseño de la programación musical, la dirección de compañías, la promoción de la prima donna como una primera figura, la formulación, regulación y judicialización de contratos laborales, la venta y alquiler de instrumentos, entre otros. 


\section{Q Bibliografía}

" Almeida, L. Cardoso de (2011). O Som social: Música, poder e sociedade no Brasil (Rio de Janeiro, séculos XVIII e XIX). San Pablo: Edición del autor.

"Allier, R. (2008). ¿Qué es esto de la ópera? Introducción al mundo de la lírica. Madrid: Robinbook.

" Aspell, M. (1992). El espejo de la vida" La regulación del teatro porteño en la primera mitad del siglo XIX. Revista de Historia del Derecho, 21, pp. 75-96.

" Batticuore, G. y Gallo, K. (2013). Ideas, literatura y opinión pública. En: Ternavasio, M. (Dir.) Historia de la Provincia de Buenos Aires. De la organización provincial a la federalización de Buenos Aires (1821-1880). Buenos Aires: UNIPE- Edhasa, pp. 317-348.

" Bensa, A. (2015). De la microhistoria a una antropología crítica. En: Revel, J., (Dir.) Juegos de escalas. Experiencias de microanálisis. Buenos Aires: UNSAM Edita, pp. 45-86.

" Benzecry, C. (2017). ¿Como pez en el agua? Aporías de la sociología disposicional. Cuestiones de Sociología, 16, e026.

"Bosch, M. (1905). Historia de la ópera en Buenos Aires: Origen del canto i la música. Las primeras compañías i los primeros cantantes. Buenos Aires: El Comercio.

" Bourdieu, P. (1986). L' illusion biographique. En Actes de la recherche en sciences sociales, 62-63 (1), pp. 69-72.

" Bourdieu, P. (1991). El sentido práctico. Madrid: Taurus.

" Carredaño, C. y Eli, Victoria (2010). El teatro lírico. En: Carredaño, C.; Eli, V. (Eds.) Historia de la música en España e Hispanoamérica. La música en Hispanoamérica en el siglo XIX. Vol. VI. Madrid: Fondo de Cultura Económica, pp. 153-219.

"Corcuff, P. (2014). Las nuevas sociologías. Principales corrientes y debates, 1980-2010. Buenos Aires: Siglo Veintiuno.

"Djenderedjian, J. C. (2015). Estructura productiva, comercio y transportes. De la primera expansión ganadera al acelerado desarrollo de la segunda mitad del siglo XIX. En: Ternavasio, M. (Dir.) Historia de la Provincia de Buenos Aires. De la organización provincial a la federalización de Buenos Aires (1821-1880). Buenos Aires: UNIPE- Edhasa, pp.117-153.

" Dosse, F. (2007). El arte de la biografía: entre historia y ficción. México: Universidad Iberoamericana.

" Elias, N. (1991). Mozart. Sociología de un genio. Barcelona: Península.

" Farías Vazquez, M. (2015). Pretensiones culturales de la oligarquía chilena en el siglo XIX, el caso de la ópera. Revista NEUMA, 8 (2), pp. 110-132.

" Gallo, K. (2012). Bernardino Rivadavia. El primer presidente argentino. Buenos Aires: Edhasa.

" Gesualdo, V. (1961). Historia de la Música en la Argentina. Tomo I. Buenos Aires: Beta.

" Goyena, H. (2003). Lírica a la luz de las velas: la ópera en Buenos Aires entre 1821 y 1830. Revista Música e Investigación. Instituto Nacional de Musicología "Carlos Vega", 12-13 (1).

" Guinzburg, C. (2014). El hilo y las huellas. Lo verdadero, lo falso, lo ficticio. Buenos Aires: Fondo de Cultura Económica.

" Guillamon, G. (2015a). La cultura teatral porteña y la Sociedad del Buen Gusto: una aproximación desde los escritos de Fray Camilo Henríquez en El Censor. Coordenadas. 
Revista de Historia Local y Regional, 2, pp. 30-51

" Guillamon, G. (2015b). De la programación miscelánica a la consolidación de la ópera. Devenir y conformación del gusto musical en Buenos Aires (1821-1828). Anuario del Instituto de Historia Argentina, núm. 15.

" Guillamon, G. (2016). El buen gusto como ideario normativo: el caso de la cultura musical durante el periodo rivadaviano (1820-1827). Revista Cuadernos del sur. Historia,43.

" Guillamon, G. (2017). Gusto y buen gusto en la cultura musical porteña (1820-1828). Prismas. Revista de historia intelectual, Centro de Historia Intelectual, 21, pp. 33-51.

" Guillamon, G. (2018) Del esplendor de la ópera al éxito de la canción: música y romanticismo en Buenos Aires durante 1830 En: Anuario IEHS, 33 (2), pp. 189-207.

" Guillamon, G. (2019). ¡Qué bien conoce la escena! ¡Cómo siente la fuerza de cada nota!: Mujeres cantantes, agencia y representaciones sociales en Buenos Aires (1820-1830). Cuadernos Fhycs-UnJu, 53.

" Johnson, J. (1995). Listening in Paris: a cultural history. Berkeley: University of California Press.

" Lahire, B. (2004). El hombre plural. Los resortes de la acción. Barcelona: Edicions Bellaterra.

" Latour, B. (2008). Reensamblar lo social. Una introducción a la teoría del actor-red. Buenos Aires: Manantial.

" Love, G. T. (2014). Cinco años en Buenos Aires. Buenos Aires: Claridad.

"Molina, E. (2006). Algunas consideraciones sobre la teoría del espacio público. Revista de Estudios Contemporáneos, 1, pp. 99 - 118

" Mugayar Kühl, P. (2003). Cronología da Opera no Brasil. - séculoXIX (Rio de Janeiro). Campiñas: CEPAB-Instituto de Artes- UNICAMP.

" Myers, J. (1999). Una revolución en las costumbres: las nuevas formas de sociabilidad de la élite porteña, 1800-1860. En: Devoto, F. y Madero, M. (dirs.). Historia de la vida privada en la Argentina. País antiguo. De la colonia a 1870. Buenos Aires: Taurus, 111-145.

"Nussbaum, M. (2014) Emociones políticas: ¿Por qué el amor es importante para la justicia? México: Paidós.

" Osterhammel, J. (2015) La transformación del mundo. Una historia global del siglo XIX. Barcelona: Crítica, 5-9.

"Passeron, J-C. (1990). Biographies, flux, itineraires, trajectoires. Revue Française de Sociologie, 31 (1), pp. 3-22

"Pereira Fernandez, A. (2011). Notas para jugar con la ilusión biográfica y no perderse en el intento. Revista Científica Guillermo de Ockham. 9 (1), pp. 105-122.

"Plesch, M. y Huseby, G. (1999). La música desde el período colonial hasta fines del siglo XIX. En: Burucúa, J. E. (Comp.) Nueva historia argentina.Arte, sociedad y política. Buenos Aires: Sudamericana, pp. 219-268.

"Salgado, S. (2003). The TeatroSolís. 150 years of Opera, Concert and Ballet in Montevideo. Estados Unidos: Wesleyan University Press.

"Zanolli Fabila, B. (1997). La profesionalización de la enseñanza musical en México: el Conservatorio Nacional de Música (1866-1966). Su historia y vinculación con el arte, la ciencia y la tecnología en el contexto nacional. Tesis doctoral defendida en la Universidad Nacional Autónoma de México.

"Zarlenga, M. (2014). La nacionalización de la Academia de Bellas Artes de Buenos Aires (1905-1907). Revista Mexicana de Sociología, 76 (3), pp. 383-411. 